\title{
A EDUCAÇÃO FÍSICA E AS POSSÍVEIS INTERDISCIPLINARIDADES NOS ANOS INICIAIS DO ENSINO FUNDAMENTAL
}

\author{
C. S. COSTA*, M. I. MONTEIRO \\ Instituto Federal de Educação, Ciência e Tecnologia de Mato Grosso do Sul \\ catia.costa@ifms.edu.br*
}

Artigo submetido em 11/01/2017 e aceito em 20/11/2019

DOI: $10.15628 /$ holos.2019.5539

\section{RESUMO}

Este artigo discute possibilidades de articulação entre as diferentes linguagens com base na linguagem corporal como meio para o desenvolvimento da especificidade da Educação Física nos anos iniciais do Ensino Fundamental. Essa discussão se fundamenta nos resultados de uma dissertação de mestrado em educação, desenvolvida mediante um estudo de caso como uma das possibilidades de pesquisa qualitativa, com uso de observações, entrevistas e análise de documentos. As características elucidadas no eixo "conteúdo escolar" contemplam os processos de alfabetização e letramento, possibilitam a articulação/fortalecimento entre áreas e se relacionam com as questões das políticas públicas de formação de professores de Educação Física. Consideramos que a forma como a participante da pesquisa de mestrado desenvolveu o conteúdo nas aulas se aproxima de um "pensar" e de um "fazer"
\end{abstract}

interdisciplinar, em virtude do diálogo com outros modos de conhecer, do compromisso com a aprendizagem discente, da atitude de busca e pesquisa, do uso da linguagem corporal como possibilidade de comunicação, da diversificação dos procedimentos para ensinar etc. Algumas aproximações foram feitas entre os dados da pesquisa de mestrado e debates atuais, uma vez que o trabalho docente em qualquer área exige ações interdisciplinares. Assim, este artigo apresenta reflexões a respeito de interdisciplinaridade e indagações que podem apontar possíveis avanços na compreensão e no fazer pedagógico do que é ou possa ser interdisciplinar. Portanto, o debate referente a possibilidades de boas práticas no contexto de início da carreira e a necessidade de políticas públicas de formação docente é consolidado pelas análises realizadas.

PALAVRAS-CHAVE: Articulação entre as Linguagens, Linguagem corporal, Boas Práticas na Educação Física, Anos Iniciais do Ensino Fundamental, Formação de Professores.

\section{PHYSICAL EDUCATION AND POSSIBLE INTERDISCIPLINARITIES IN THE INITIAL YEARS OF FUNDAMENTAL EDUCATION}

\begin{abstract}
This article discusses possibilities of articulation among different languages based on body language as a means for the development of the specificity of Physical Education in the initial years of Elementary School. This discussion is based on the results of a Master's thesis in education, developed through a case study as one of the possibilities of qualitative research, using observations, interviews and document analysis. The characteristics elucidated in the axis "school content" contemplate the processes of literacy and literacy, enable the articulation / strengthening between areas and relate to the issues of public policies for the training of Physical Education teachers. We consider that the way in which the participant in the master's research developed the content in the classes approaches an interdisciplinary "thinking" and "doing", due to the
\end{abstract}

dialogue with other ways of knowing, commitment to student learning, attitude search and research, use of body language as a possibility of communication, diversification of procedures for teaching, etc. Some approximations were made between the data of the master's research and current debates, since the teaching work in any area requires interdisciplinary actions. Thus, this article presents reflections on interdisciplinarity and inquiries that may point out possible advances in the understanding and pedagogical doing of what is or may be interdisciplinary. Therefore, the debate regarding the possibilities of good practices in the context of the beginning of the career and the need for public policies of teacher training is consolidated by the analyzes carried out. 


\section{INTRODUÇÃO}

Com o objetivo de elucidar possibilidades de articulação entre as diferentes linguagens subsidiadas pela linguagem corporal como meio para o desenvolvimento da especificidade da Educação Física nos anos iniciais do Ensino Fundamental -, organizamos este artigo tomando-se por base os resultados de uma dissertação de mestrado em educação (COSTA, 2014).

Por se tratar de um recorte, nossa discussão se fundamenta, neste artigo, nos resultados do eixo "conteúdo escolar", no qual buscamos distinguir diversos elementos que podem contribuir para essas possibilidades de articulação por meio do diálogo entre as áreas do conhecimento nesse nível de ensino. Igualmente, buscamos entender como uma área pode, mediante o desenvolvimento de sua especificidade, colaborar e garantir, ao mesmo tempo, o desenvolvimento de outras áreas.

Nesse propósito, ansiamos, em face da análise dos resultados da dissertação (COSTA, 2014), elucidar diversas características das práticas de uma professora de Educação Física iniciante que colaboram para uma perspectiva interdisciplinar de ensino, embora não tenha sido esse o foco principal da pesquisa de mestrado e, tampouco, considerado como especificidade nas práticas analisadas.

Corroborando Fazenda (1996, p. 17), entendemos o pensamento interdisciplinar com base no

[...] princípio de que nenhuma forma de conhecimento é em si mesma racional. Tenta, pois, o diálogo com outras formas de conhecimento, deixando-se interpenetrar por elas. Assim, por exemplo, aceita o conhecimento do senso comum como válido, pois é através do cotidiano que damos sentido às nossas vidas. Ampliado através do diálogo com o conhecimento científico, tende a uma dimensão utópica e libertadora, pois permite enriquecer nossa relação com o outro e com o mundo. (FAZENDA, 1996, p. 17).

Para a autora, pensar interdisciplinarmente requer um planejamento no qual haja concordância entre razão e propósito. Nessa perspectiva, é possível apreender a complexidade nas relações entre indivíduos e entre indivíduos e objetos, desde que tal planejamento não seja imposto e não esteja orientado apenas pela ideia de produção, mas que se manifeste, no cotidiano, com base em uma atitude espontânea, emergido de uma proposta, de um "ato de vontade" em relação ao conhecimento que se pretende ampliar (FAZENDA, 1996).

A possibilidade de desenvolvimento de um trabalho articulado entre a Educação Física e as demais áreas do conhecimento no Ensino Fundamental já foi apresentada por Silva (1996), mediante as seguintes reflexões: as dificuldades existentes nessa articulação; as origens dessas dificuldades (mais acentuadas na Educação Física em razão de dúvidas na legalidade da disciplina na época, da formação de natureza biológica, da desvalorização da disciplina por docentes de outras áreas e da realização das aulas em horários e locais diferentes das aulas das demais disciplinas); a inserção da Educação Física na área de Comunicação e Expressão; e o papel da 
Educação Física enquanto componente curricular com base em objetivos educacionais mais amplos.

Não obstante, a autora assegura que essas dificuldades não limitam a possibilidade de articulação entre as áreas, desde que a consciência do professor de Educação Física esteja "[...] voltada para os objetivos gerais da Educação que ele, enquanto componente de um corpo docente, deveria estar contribuindo para alcançar" (SILVA, 1996, p. 65, grifo da autora). Corroborando a autora, Santos, Marcon e Trentin (2012) também apontam dificuldades no desenvolvimento de um trabalho interdisciplinar e de reconhecimento da Educação Física na área de Linguagens, Códigos e suas Tecnologias (LCT), conforme proposto nos Parâmetros Curriculares Nacionais (PCN) para o Ensino Médio (BRASIL, 2000) e no Currículo do Estado de São Paulo (SÃO PAULO, 2011a) para os anos finais do Ensino Fundamental e para o Ensino Médio. Faz-se necessário afirmar que tanto os autores quanto os documentos supracitados neste parágrafo apresentam tal perspectiva mediante a expressão "LCT", o que difere, por exemplo, das orientações apresentadas pela Base Nacional Comum Curricular, BNCC (BRASIL, 2016).

Proveniente de uma exigência legal, a BNCC apresenta-se como proposta de melhoria educacional. As etapas da escolarização se organizam, na Educação Infantil, por meio de "campos de experiências" (a linguagem se faz presente em alguns desses campos) e, no Ensino Fundamental e Médio, por meio de áreas do conhecimento. Para o Ensino Fundamental de nove anos, há a definição de "eixos de formação", cujo objetivo consiste em integrar diferentes componentes curriculares e áreas do conhecimento. A área de linguagens é uma das áreas do conhecimento presentes no documento, na qual a Educação Física é um dos componentes curriculares.

Segundo Ladeira (2007), nessa perspectiva, o uso da linguagem nas aulas de Educação Física no Ensino Fundamental e Médio é apresentado como meio para o desenvolvimento da especificidade da área. Os professores investigados pela autora, apesar de apresentarem conhecimentos superficiais a respeito da linguagem (e outros conceitos) em suas possibilidades de relações com a Educação Física, a desenvolvem de forma não planejada em suas aulas, pois não a concebem como conteúdo ou objetivo. Essa concepção pode estar enraizada em uma função ainda indefinida da linguagem no contexto escolar (LADEIRA, 2007).

Igualmente, localizamos alguns estudos referentes às contribuições das aulas de Educação Física no processo de alfabetização nos anos iniciais do Ensino Fundamental (CORDEIRO; CORDEIRO, 2015; MENEGON et al., 2015). Melo (2006) discute essas relações no contexto da Educação de Jovens e Adultos (EJA), mas na perspectiva do letramento. Essa discussão não é recente, pois Petry (1988) já demonstrou essa preocupação ao repensar a Educação Física nos anos iniciais para além de uma perspectiva recreativa e apresentou possibilidades que, simultaneamente, contribuem para desenvolver a especificidade da área e alfabetizar os alunos desse nível de ensino.

Portanto, com o desígnio de realizarmos o objetivo deste artigo, assim estruturamos este trabalho: neste primeiro tópico apresentamos nossa opção temática, objetivos e possíveis contribuições; no segundo tópico apresentamos a revisão bibliográfica e a metodologia para 
proporcionar visibilidade no que se refere ao desenvolvimento da pesquisa de mestrado e situar o leitor a respeito dos dados coletados e analisados; no terceiro tópico, discutimos com os resultados do eixo de análise "conteúdo escolar"; e, no quarto tópico, apresentamos as características que podem contribuir para o diálogo entre as áreas com base em boas práticas nas aulas de Educação Física nos anos iniciais do Ensino Fundamental.

\section{REVISÃO BIBLIOGRÁFICA E METODOLOGIA}

No intento de conhecer e compreender as práticas pedagógicas de uma professora de Educação Física iniciante e as fontes que influenciam na construção de seus saberes, a pesquisa de mestrado (COSTA, 2014) trouxe foco para evidências que, salvo exceções (GUARNIERI, 2005; LEAL, 2011), não são apontadas pela literatura referente ao início da carreira.

Mediante um estudo de caso (ANDRÉ, 1998) representativo com a participante, foi possível evidenciar aspectos positivos do período de inserção na docência. A dissertação, produzida com base em considerações a respeito do início da carreira como uma fase complexa e pouco explorada (HUBERMAN, 1995; NONO, 2011) e nos professores iniciantes (COSTA; VOLTARELLI; CUNHA, 2012), apresentou o desenvolvimento de práticas pouco comuns nesse período da carreira. Essas práticas se fundamentam em uma perspectiva contextualizada e interdisciplinar de ensino, as quais possibilitam a ressignificação da aprendizagem dos alunos para "além da prática", com propostas de atividades com planejamento, objetivos e significados próprios da Educação Física enquanto "componente curricular" nos anos iniciais do Ensino Fundamental.

A professora de Educação Física foi escolhida por se encontrar em seu quarto ano de atuação profissional, por sua condição de efetiva na rede de ensino estadual paulista, sua atuação com os anos iniciais e sua disponibilidade para a pesquisa. Desses 4 anos, os 2 primeiros foram exercidos na rede de ensino municipal e, os 2 últimos, em 2 escolas da rede de ensino da Secretaria da Educação do Estado de São Paulo (SEDUC) concomitantemente. Assim, com base em Huberman (1995), a participante se encontrava, no momento da pesquisa, em um processo de transição entre a "exploração" e a "estabilização". Licenciada em Educação Física pela Universidade Estadual Paulista (UNESP), em 2007, a professora realizou especialização em Educação Física Escolar pela Universidade Federal de São Carlos (UFSCar), em 2010, e participou de cursos e congressos ao longo de sua trajetória formativa e profissional, inclusive durante o período de realização da coleta de dados.

O início da carreira pode ser entendido pela "exploração", etapa que se assemelha a uma temporada de descoberta, na qual o professor conhece e compreende, gradativamente, os meandros que compõem o exercício da docência e as caraterísticas que se fazem presentes no contexto em que se insere (HUBERMAN, 1995). Para o autor, na "exploração" pode-se identificar tanto a "sobrevivência" (aspectos impactantes, impasses, percepção e constatação da complexidade e imprevisibilidade da docência) quanto a "descoberta" (aspectos menos penosos, animação pela entrada na carreira, oportunidade de poder experimentar e se posicionar como uma pessoa responsável e por ser/fazer parte de um grupo). 
Ainda que não seja comum, Guarnieri (2005) e Leal (2011) evidenciaram boas práticas nesse período. Em Leal (2011), a experiência docente nem sempre está relacionada ao tempo de atuação, pois somente a quantidade de anos não garante essa experiência. $O$ autor apresenta resultados de sua pesquisa com um professor de Educação Física iniciante e, ao mesmo tempo, experiente, em razão das boas práticas desenvolvidas nos anos iniciais. Já Guarnieri (2005) apresenta a ocorrência de 3 implicações para o professor iniciante com base nas perspectivas dos próprios professores. A primeira representa a rejeição dos conhecimentos da formação inicial, a concessão à cultura escolar e a adoção de uma postura passiva. A segunda representa uma postura técnica, de aplicação, na tentativa de transportar os conhecimentos da teoria para a prática. E a terceira se remete a uma postura de questionamento, a qual não é uma tendência predominante nas situações em que ocorre o início da carreira.

As dificuldades do professor de Educação Física iniciante são, de acordo com Ferreira e Reali (2009), semelhantes aos professores de outras áreas, exceto pelas questões relativas à especificidade da disciplina. Diversos estudos (AGUIAR et al., 2005; BORGES, 2005; CLARO Jr.; FILGUEIRAS, 2009; LADEIRA; DARIDO, 2003; SILVA, 1996) afirmam que essas dificuldades sobretudo na relação teoria-prática - são consequências de prováveis lacunas dos cursos de formação inicial. Em virtude dessas dificuldades, faz-se necessário voltar olhares para os saberes que são construídos pelos professores iniciantes e não somente para as particularidades dos momentos de ingresso na docência.

A formação inicial em Educação Física apresenta, de acordo com Borges (2005), uma continuidade do sistema aplicacionista de ensino, o qual não contempla as necessidades formativas dos docentes em exercício. Em razão dessa constatação, foi importante ressaltar, na dissertação, o Parecer 009/2001', do Conselho Nacional de Educação (CNE), o qual apresentou preceitos norteadores extensos e diretivas para uma política de formação docente, de organização temporal e espacial e de composição dos cursos (BRASIL, 2001b).

Em relação à formação do professor, é válido mencionar a Resolução n. 2, de 1 de julho de 2015 (BRASIL, 2015), do CNE, que deliberou as Diretrizes Curriculares Nacionais (DCN) para a formação inicial e continuada. Na Resolução, a formação inicial - entendida como nível superior de ensino -, compreende os cursos de licenciatura, bem como a formação pedagógica e segunda licenciatura para graduados. Nossa intenção consiste em atualizar, com base nas disposições gerais da Resolução, o debate a respeito da formação de Profissionais do Magistério para a Educação Básica, cujos princípios, planejamentos e procedimentos das políticas e da gestão dos programas e cursos de formação devem se configurar com base em uma ideia de articulação/colaboração entre o MEC, as instituições formadoras e sistemas e redes de ensino e suas instituições. Assim, as DCN da formação inicial e continuada devem possibilitar que as particularidades nas diferentes etapas (Educação Infantil, Ensino Fundamental e Ensino Médio) e modalidades (Educação de Jovens e Adultos, Educação Especial, Educação Profissional e Tecnológica, Educação do Campo, Educação Escolar Indígena, Educação a Distância e Educação Escolar Quilombola) de educação básica, sejam atendidas. Dentre várias disposições, a Resolução, delibera, em seu Artigo 3으, § 5으, a respeito de: reconhecer as instituições de educação básica como espaços formativos imprescindíveis aos profissionais do magistério; e entender a formação 
contínua como aspecto indispensável da profissionalização docente com base na diversidade de saberes e na experiência, integrando a formação ao cotidiano e ao Projeto Político Pedagógico (PPP) da instituição de educação básica.

As deliberações supracitadas - Artigo 3으, § 5ㅇ - corroboram as assertivas de Tardif (2008) referentes à iniciação e ao desenvolvimento na docência, os quais implicam em apropriação de saberes objetivos e exclusivos dos contextos de trabalho, incluindo hábitos, normas e valores. Em razão desses efeitos, faz-se necessário estabelecer relações entre os saberes e o início da carreira, uma vez que, conforme o autor, os saberes docentes são construídos de forma intensa e acentuada no início da carreira, entre os 3 ou os 5 primeiros anos, e podem orientar todos os saberes imprescindíveis à atuação docente.

Assim, refletir com base no início da carreira é tão importante quanto refletir a respeito do início da carreira na Educação Física, haja vista a necessidade de legitimação dessa área do conhecimento na escola como "componente curricular" pelas vias legais (BRASIL, 1996, 2001a, 2007; GALLARDO, 2010). Em relação à área, faz-se necessário mencionar o processo que permeou sua trajetória enquanto prática pedagógica e influenciou na organização da Lei de Diretrizes e Bases da Educação Nacional, LDB-EN (BRASIL, 1996) e na formulação dos PCN de Educação Física para o ensino de 1ạ. a 4a série (BRASIL, 1997), a saber: a concepção de Educação Física como "atividade física" arraigada em uma visão biológica expandida para uma consideração pelo ser humano em sua totalidade. Em face desse processo, foi possível observar a configuração das leis com base na trajetória da área, por meio de uma Educação Física concebida como "atividade física" a uma Educação Física concebida como "componente curricular obrigatório" e integrada ao PPP de cada escola (BRASIL, 1996, 2001a).

A formação do professor de Educação Física fundamentada nessa visão biológica comprometeu, de acordo com Silva (1996), a possibilidade de desenvolvimento de um trabalho articulado entre as áreas do conhecimento no contexto escolar. Logo, Ladeira e Darido (2003) afirmam que uma quase exclusividade dessa perspectiva biológica foi observada na atuação docente.

Com base na legislação, faz-se indispensável destacar, também, a ampliação do Ensino Fundamental de 8 para 9 anos conforme a Lei 11.274/2006, cujo objetivo consistiu em ampliar a permanência obrigatória na escola e melhorar os resultados das avaliações externas (BRASIL, 2007). Essa intenção de melhoria também voltou olhares para a qualidade do ensino e para a atuação docente, uma vez que a SEDUC, por meio do Programa "Mais Qualidade na Escolai", criou a Escola de Formação e Aperfeiçoamento dos Professores (EFAP) do Estado de São Paulo para proporcionar formação contínua e em serviço aos docentes. Algumas mudanças foram determinadas para o acesso ao quadro do magistério, mediante 3 fases de concurso público: avaliação objetiva; prova de títulos; Curso de Formação Específica (EFAP); e exame de aptidão (SÃO PAULO, 2011b). A professora de Educação Física iniciante - participante da pesquisa de mestrado - participou desse processo, tornando-se docente dentro dessa nova política educacional. 
Com base no objetivo supracitado, a dissertação foi desenvolvida por meio de um estudo de caso com essa professora como uma das possibilidades de pesquisa qualitativa (ANDRÉ, 1998; BOGDAN; BIKLEN, 1994). Essa pesquisa de mestrado foi avaliada como qualitativa por ser composta por entrevistas e observação participante (BOGDAN; BIKLEN, 1994), constituindo-se, em um "[...] estudo descritivo de uma unidade, seja uma escola, um professor, um aluno ou uma sala de aula" (ANDRÉ, 1998, p. 30).

A relevância do estudo profundo das práticas dessa professora se justifica na medida em que se constitui em um estudo de caso representativo de uma professora iniciante, com foco em evidências que, normalmente, não são apontadas pela literatura referente ao início da carreira. Para tanto, foram empregados os seguintes instrumentos de coleta de dados: entrevistas semiestruturadas; observação participante; e análise documental. Esses instrumentos distinguem a pesquisa qualitativa (ANDRÉ, 1998; BOGDAN; BIKLEN, 1994) e foram utilizados mediante apreciação e aprovação da proposta dessa pesquisa de mestrado pelo Comitê de Ética em Pesquisa (CEP) em Seres Humanos da UFSCar, no processo 72184.

Junto às entrevistas semiestruturadas (realizadas em 4 momentos da pesquisa, de maio de 2012 a março de 2013), observações e análises de documentos, o envolvimento da professora em cursos e congressos na área da Educação Física também foi observado. As entrevistas tiveram como objetivo investigar a fundo as questões estudadas, informando a respeito dos problemas analisados minuciosamente (ANDRÉ, 1998).

As observações das práticas da participante foram realizadas, concomitantemente, em 2 escolas estaduais, denominadas, respectivamente, de Escola 1 (escola-sede da participante, unidade onde seu cargo de Professor de Educação Básica II, PEB-II, estava lotado) e Escola 2 (unidade onde a participante possuía aulas em carga suplementar). Essas observações abarcaram o desenvolvimento de noventa (90) aulas e ocorreram ao longo do segundo semestre de 2012. $\mathrm{Na}$ Escola 1, foram observadas setenta (70) aulas com terceiros, quartos e quintos anos e 2 Aulas de Trabalho Pedagógico Coletivo (ATPC) e, na Escola 2, foram observadas vinte (20) aulas com terceiros anos.

A observação participante permitiu uma sucessiva ação mútua entre pesquisador e a situação investigada, com base no pressuposto de que existe sempre uma situação de interação entre ambos, de modo a transformar tal situação e ser por ela também transformado (ANDRÉ, 1998). Alguns aspectos também foram privilegiados e registrados em "notas de campo", como a forma como as aulas aconteciam, em relação aos critérios de planejamento, seleção dos conteúdos, objetivos das atividades, subsídios teóricos e metodológicos, estratégias, relações entre os atores do ambiente escolar etc. As "notas de campo" compreendem "[...] o relato escrito daquilo que o investigador ouve, vê, experiencia e pensa no decurso da recolha [...]" dos dados (BOGDAN; BIKLEN, 1994, p. 150).

Já os documentos foram utilizados para constituir o fato no seu todo, complementando os conhecimentos extraídos dos dados coletados (ANDRÉ, 1998). Os PPP das escolas, junto à legislação para o ensino da Educação Física nos anos iniciais, ao Plano de Ensino Anual (PEA), caderno de planejamento, atividades, livros, filmes, textos, registros dos alunos etc., também 
foram analisados. Do mesmo modo, a professora iniciante e as 2 escolas envolvidas foram caracterizadas, bem como o processo de construção dos eixos de análise.

As duas escolas atendem alunos dos anos iniciais (com níveis socioeconômicos pertencentes a classes populares) e seus PPP encontravam-se organizados em um período de 4 anos. A Escola 1 articula a aprendizagem com sua função social, respeitando as particularidades da comunidade local. Para a equipe gestora, o PPP é um processo em contínua (re) construção. No entanto, o documento não faz referências específicas às áreas do conhecimento. Em síntese, contempla a identificação da escola, princípios, finalidades, concepções, ações, operacionalização e considerações finais. O PPP da Escola 2 apresenta-a mediante proposições de competências e habilidades para os anos iniciais, objetivos gerais em todas as áreas, autoavaliação, currículo, processos para as normas regimentais, planos de ensino, sistema organizacional, avaliação e anexos.

Em face das reflexões suscitadas pelas leituras anteriores para a redação da dissertação (COSTA, 2014) e da riqueza das informações obtidas, emergiram-se os eixos para análise dos dados, identificados e construídos antes e durante a pesquisa de campo. Os eixos são construídos com base em regularidades e temas observados nos dados e representados por "frases-chave" que expressam seus teores (BOGDAN; BIKLEN, 1994). Os autores afirmam que alguns eixos podem emergir na medida em que os dados são coletados, sendo decisivo o desenvolvimento dos eixos para a organização dos dados.

A opção, neste artigo, pela discussão com o eixo "conteúdo escolar" (assunto do próximo tópico) se fundamenta no próprio teor desse eixo ("o que ensina", "como ensina" e "porque ensina"), o qual certamente apresenta mais elementos que possam contribuir para o objetivo aqui delineado.

Portanto, apresentamos a seguir, uma discussão com base no eixo "conteúdo escolar". Conforme diversos estudos (CORDEIRO; CORDEIRO, 2015; COSTA; MONTEIRO, 2016; LADEIRA, 2007; LADEIRA; DARIDO, 2003; MENEGON et al., 2015; PETRY, 1988; SILVA, 1996), igualmente confiamos na possibilidade de articulação entre as áreas e nas contribuições das aulas de Educação Física para o desenvolvimento de outras áreas com base nas características identificadas nas boas práticas desenvolvidas pela participante da pesquisa de mestrado (COSTA, 2014).

\section{RESULTADOS E DISCUSSÕES}

Na Educação Física, os conteúdos constituem a "cultura corporal", apresentada por Castellani Filho et al. (2009) como o resultado dos conhecimentos produzidos pelo homem, criados pela história e desenvolvidos pela cultura. Os autores confirmam que algumas dessas produções - Jogos, Ginásticas, Esportes, Lutas e Danças - foram abrangidas pela Educação Física.

Os PCN de Educação Física para o ensino de 1a a 4ạ série (BRASIL, 1997) também apresentam a "cultura corporal" como resultado de uma produção social. O documento propõe que os conteúdos da Educação Física sejam desenvolvidos com base nas dimensões conceituais 
(referente a códigos, acontecimentos e opiniões), atitudinais (associada a princípios, valores e atitudes) e procedimentais (vinculada ao fazer corpóreo, ao experimento prático). Assim, os conteúdos não devem ser considerados apenas pelas suas dimensões procedimentais, sendo necessário mudar o foco "[...] para uma concepção mais abrangente, que contemple todas as dimensões envolvidas em cada prática corporal" (BRASIL, 1997, p. 27).

A mudança de foco também se fundamenta em uma tentativa de superação de uma cultura de valorização da dimensão procedimental nas aulas de Educação Física (BRASIL, 1997; PETRY, 1988; SÃO PAULO, 2008). Esse posicionamento foi observado na participante da pesquisa de mestrado no desenvolvimento de suas práticas e na análise do PEA (COSTA, 2014). 0 desenvolvimento do conteúdo com base nas suas dimensões, além de tornar a aprendizagem mais significativa, revela o compromisso docente para com a aprendizagem discente. A proposição e o desenvolvimento do conteúdo nesse formato também vêm ao encontro da necessidade de legitimação da Educação Física na escola (BRASIL, 1996, 2001a, 2007; GALLARDO, 2010; KAWASHIMA, 2010; PETRY, 1988).

O PEA da participante para os terceiros e quartos anos propõe o desenvolvimento dos conteúdos com base nas dimensões procedimentais, conceituais e atitudinais e está organizado por bimestres, a saber: Conhecimentos a respeito do Corpo e Jogos no 10 bimestre; Conhecimentos a respeito do Corpo, Jogos e Atividades Rítmicas e Expressivas no 20 bimestre; Brincadeiras Populares e Atividades Rítmicas e Expressivas no 3 bimestre; e Ginástica Artística, Ginástica Rítmica e Jogos Africanos no 40 bimestre (COSTA, 2014). Alguns conteúdos são recorrentes no PEA para os quintos anos: Conhecimentos a respeito do Corpo e Jogos no 1 o bimestre; Jogos e Atividades Rítmicas e Expressivas no 2으 bimestre; Brincadeiras Populares no 3으 bimestre; e Jogos de Salão no 4으 bimestre.

Os PCN de Educação Física propõem os conteúdos para serem trabalhados nas aulas de Educação Física durante as séries iniciais organizados em 3 blocos: Esportes, Jogos, Lutas e Ginásticas; Atividades Rítmicas e Expressivas; e Conhecimentos Sobre o Corpo (BRASIL, 1997). A forma como o PEA está organizado se coaduna com as proposições do documento supracitado, pois há a apresentação do conceito de "cultura corporal", semelhanças na construção dos objetivos, nos conteúdos selecionados e no modo como foram propostos ao longo dos bimestres (COSTA, 2014).

Os conteúdos desenvolvidos nos anos iniciais foram selecionados e organizados pela participante de acordo com a faixa etária e os anos de escolaridade dos alunos, de acordo com as adaptações dos conteúdos propostos e de acordo com o diálogo estabelecido com algumas referências teóricas e metodológicas que fundamentam suas escolhas e o planejamento dessas escolhas (COSTA, 2014). Essas opções revelam sua própria sistematização dos conteúdos. A sistematização dos conteúdos se refere a domínios que vão além da especificidade da área, à forma de organizá-los, aos procedimentos apropriados para seus enfoques nas aulas e aos saberes relativos ao "como" dar aula.

Nos discursos e ações da professora de Educação Física, foi possível constatar considerações pela "cultura corporal" dos alunos, propostas inter-relacionadas com essa cultura, 
nas quais o espaço e o tempo das aulas promovem um aprofundamento e uma ampliação do entendimento relativo a essas práticas e seus contextos. Conforme Fazenda (1996), podemos compreender a "cultura corporal" dos alunos como um conhecimento do senso comum, cuja validade e sentido podem ser aprofundados com base em propostas escolares que se utilizem do diálogo entre a cultura escolar e a cultura dos alunos.

A inserção da Educação Física na área de linguagens se justifica, por exemplo, “[...] pelo uso da linguagem corporal - que estimula a comunicação em distintas culturas e contextos - como elemento central no processo de interação dos alunos com a cultura corporal [...]" (SANTOS; MARCON; TRENTIN, 2012, p. 572, grifo nosso). Essa prática de ensino revela uma relação, também, com as áreas de História e Geografia. Confirmando Ladeira (2007) e Costa e Monteiro (2016), as práticas da participante da pesquisa de mestrado contêm elementos que vinculam a Educação Física à linguagem, porém esta é desenvolvida como meio e não como conteúdo ou objetivo específico da área.

Para organizar e planejar suas aulas, a professora participante se fundamentou nos conteúdos "clássicos" da Educação Física como "[...] aqueles que não perdem sua atualidade para participação, compreensão e interpretação do mundo universal e particular do trabalho e da prática social intencional" (ROSÁRIO; DARIDO, 2005, p. 169).

As propostas da participante, desenvolvidas por meio de pesquisas realizadas pelos alunos com seus pais e/ou familiares a respeito de "Jogos, Brinquedos e Brincadeiras Populares", resgatam a cultura local, a aproximam da cultura escolarizada e promovem o desenvolvimento de práticas contextualizadas de ensino. Gallardo (2010) assevera que o Currículo da SEDUC (SÃO PAULO, 2011a) se fundamenta nessa perspectiva, pela apropriação mais fácil do conhecimento pelos alunos por fazer sentido em um conjunto de apreciações, conhecimentos e atividades.

Freire (2010) aponta a necessidade da articulação entre os mundos da escola e dos alunos, com consideração pelos saberes discentes e a proposição de atividades concretas e expressivas. Na ótica da participante, o processo de ensino e de aprendizagem acontece mediante a percepção da realidade ao seu entorno e da autopercepção dos sujeitos do grupo como protagonistas desta realidade (COSTA, 2014). Corroborando Freire (2010) e Costa e Monteiro (2016), a promoção de uma educação pautada no protagonismo do aluno por meio da construção da própria aprendizagem também foi identificada. Como exemplo, a construção de brinquedos referentes ao Folclore com materiais alternativos financiados com recursos próprios - atividade que representa a construção do conhecimento a respeito do assunto trabalhado, em uma perspectiva de valorização das atividades quando os alunos se comportam como sujeitos do/no processo de aprendizagem. Petry (1988) já anunciava a importância de oportunizar, às crianças, a construção das próprias atividades como possibilidade de desenvolvimento da criatividade.

Nesse cenário, tornou-se possível notar uma valorização dos conhecimentos prévios dos alunos, a oportunização de momentos para se posicionarem perante os colegas e socializarem seus saberes e a articulação entre os saberes dos alunos e os procedimentos convencionais planejados pela participante e utilizados na construção do brinquedo. Esse momento de estudo e reflexão relativo à construção do brinquedo promove a compreensão sobre o fazer, em uma 
superação do fazer pelo fazer. Freire (2010) apresenta a compreensão sobre o fazer como um direito do indivíduo (confirmando a função da escola de promover, simultaneamente, o fazer e o compreender) e, São Paulo (2008), assegura a importância e necessidade de se estudar e fazer Educação Física na escola.

Com base na perspectiva contextualizada de ensino, podemos afirmar a presença das seguintes características nas práticas desenvolvidas pela professora de Educação Física que subsidiam, por exemplo, o processo de aquisição da leitura e da escrita, apesar de não ser este seu objeto de ensino: uma postura docente pautada em finalidades educacionais gerais, conforme defende Silva (1996); uma necessidade de planejamento e desenvolvimento dos conteúdos nessa perspectiva contextualizada, a qual se coaduna com os pressupostos da inserção da Educação Física na área de linguagens (BRASIL, 2000, 2016; COSTA; MONTEIRO, 2016; LADEIRA, 2007; LADEIRA; DARIDO, 2003; SANTOS; MARCON; TRENTIN, 2012; SÃO PAULO, 2011a); e o desenvolvimento de pesquisas pelos alunos, proposta que, também, contempla uma perspectiva voltada para o letramento (MELO, 2006; MINAS GERAIS, 2004; MONTEIRO, 2010). Melo (2006) afirma, ainda, que o trabalho envolvendo a alfabetização e o letramento não deve ficar restrito às aulas de Língua Portuguesa, uma vez que todas as disciplinas escolares representam importante papel nesses processos.

Corroborando Melo (2006), destacamos, no caderno de apresentação para a formação do professor alfabetizador do Pacto Nacional pela Alfabetização na Idade Certa, PNAIC (BRASIL, 2012, p. 26), cujos objetivos consistem em assegurar a alfabetização plena de todas as crianças até os oito anos de idade, a seguinte assertiva: "[...] o ensino da leitura, da escrita e da oralidade precisa ser realizado de modo integrado aos diferentes componentes curriculares: Língua Portuguesa, Arte, Educação Física, História, Geografia, Matemática, Ciências".

Os resultados da dissertação (COSTA, 2014) também revelaram boas práticas em razão da proposição do conteúdo "Jogos Africanos" por meio de atividades e estratégias diversificadas e da relação desse conteúdo com o tema "Dia da Consciência Negra", proposto pela escola. Conforme os registros em "notas de campo" e as transcrições das entrevistas, a proposta desse conteúdo/tema foi desenvolvida mediante leituras de textos informativos e textos instrucionais, apresentação dos "Jogos Africanos" e suas diferentes origens, construção de tabuleiros, utilização do próprio corpo como peça do jogo, criação de novas regras pelos alunos etc.

O desenvolvimento, pela participante, dos conteúdos "Jogos, Brinquedos e Brincadeiras Populares" e "Jogos Africanos", por exemplo, elucida articulações com outras áreas e, esses conteúdos podem, também, ser trabalhados em História e Geografia.

Segundo Ladeira e Darido (2003, p. 34) "é nas aulas de Educação Física que os alunos darão início à produção de textos, à leitura dos diferentes textos corporais, compreendendo uma dança, um jogo ou um esporte". É necessário elucidar que a expressão "texto", para as autoras, apresenta uma abrangente compreensão e consiste em caracterizar unidades fundamentais que ultrapassam a linguagem falada. Petry (1988) já afirmava que 
o corpo é um campo de expressão e o movimento um meio de a expressão se realizar; e é através da educação física que a criança descobre suas possibilidades cinéticas. Expressase com seu corpo, em seu corpo, com o movimento igual ao que se faz com a palavra, a escrita ou o desenho. (PETRY, 1988, p. 16-17).

Trabalhar um conteúdo em seus diferentes aspectos e possibilidades, além de torná-lo significativo, favorecer reflexões e aprofundamento a respeito do assunto, representa compromisso com os alunos pelo domínio do conhecimento a ser ensinado em virtude de uma postura aprendente e pela eficácia da aprendizagem promovida, atributos que, nas palavras de Silva et al. (2007), correspondem ao bom professor. O domínio do conhecimento relativo ao objeto de ensino pelo professor também se constitui como um indicador educacional daquilo que deve ser proporcionado aos alunos nas aulas de Educação Física (LEAL, 2011).

Para além da necessidade do domínio do saber sobre o conteúdo, houve preocupações referentes ao domínio do saber como ensinar (BORGES, 2005; TARDIF, 2008). Os anseios da participante envolviam desde o domínio dos conteúdos até as estratégias para ensiná-los (COSTA, 2014). Nessas situações, uma das estratégias de superação consistiu na organização e no planejamento das aulas com base em uma perspectiva de ensino contextualizada e interdisciplinar, conforme Fazenda (1996), Freire (2010) e São Paulo (2011a). Com base em Fazenda (1996, p. 18), afirmamos que essas estratégias se assentam em uma "atitude interdisciplinar", caracterizada pela "[...] ousadia da busca, da pesquisa; é a transformação da insegurança num exercício do pensar, num construir".

Essa preocupação com a interdisciplinaridade pode ser observada desde Petry (1988), quando, em uma nova proposição alfabetizadora, a Educação Física e outras áreas (Artes Plásticas, Teatro, Música e Dança) foram incluídas nesse processo. "Perceber-se interdisciplinar é o primeiro movimento em direção a um 'fazer' interdisciplinar e a um 'pensar' interdisciplinar" (FAZENDA, 1996, p. 14, grifo da autora). Em conformidade com Costa e Monteiro (2016), entendemos que a inserção da Educação Física na área de linguagens pode contribuir para o seu desenvolvimento nessa perspectiva de ensino, uma vez que essa área

[...] privilegia a aquisição e o desenvolvimento de competências gerais relacionadas à representação, à comunicação, à investigação, à compreensão e à contextualização sociocultural, de modo que os alunos conheçam e saibam usar diferentes linguagens em distintas situações e contextos. (SANTOS; MARCON; TRENTIN, 2012, p. 572).

Conforme Ladeira e Darido (2003), uma participação ativa na sociedade pode ser assegurada pelo ato de refletir a respeito da linguagem. As autoras confirmam as possibilidades e deveres da Educação Física enquanto uma linguagem com base nas entrevistas realizadas com professores universitários.

Embora as características das práticas da participante da pesquisa de mestrado contribuam para a legitimação da área enquanto "componente curricular" (BRASIL, 1996, 1997; PETRY, 1988), para a aprendizagem dos alunos enquanto protagonistas nesse processo e para 0 
desenvolvimento de uma perspectiva de ensino contextualizada e interdisciplinar (FAZENDA, 1996; FREIRE, 2010; SÃO PAULO, 2011a), não se pode eximir a SEDUC de suas responsabilidades para com a formação e as condições de trabalho docente, sobretudo do professor de Educação Física iniciante.

Conforme reflexões no segundo tópico deste artigo, a participante integrou, para ingressar no quadro do magistério da SEDUC, uma nova política educacional por meio de 3 fases de concurso público (SÃO PAULO, 2011b). Uma dessas fases, composta pelo Curso de Formação Específica promovido pela EFAP, representou o estudo do Currículo da SEDUC, com contribuições teórico-metodológicas ao professor iniciante. No entanto, tais contribuições não estavam direcionadas aos anos iniciais, fato que denota uma política na contramão da formação que deve ser oferecida ao professor de Educação Física que atua nesse nível de ensino.

Assim, o professor iniciante, além de ter que enfrentar as dificuldades do início na carreira (COSTA, 2014; FERREIRA, 2006; GUARNIERI, 2005; HUBERMAN, 1995; NONO, 2011), terá que administrar as implicações da incoerência dessa formação. Essa problemática merece estudo, debate e análise pelos proponentes das políticas públicas de formação de professores, uma vez que se fazem imprescindíveis diretrizes e proposições diretamente voltadas ao ensino da Educação Física no contexto dos anos iniciais e aos cursos de formação inicial e continuada.

$\mathrm{Na}$ análise do PEA da professora de Educação Física, os conteúdos propostos perpassam os terceiros, quartos e quintos anos do Ensino Fundamental (COSTA, 2014). Porém, esses conteúdos não são referenciados nos PPP das escolas. A participante afirmou desconhecer esses documentos e, por isso, entende-se que suas construções não acontecem coletivamente, assertiva que contradiz, por exemplo, uma das proposições do PPP da Escola 1.

Em síntese, com base no eixo de análise "conteúdo escolar", observamos: práticas com atividades e estratégias diversificadas; espaço físico definido com base no conteúdo planejado; apresentação de uma ideia de continuidade nas ações planejadas e desenvolvidas; coerência entre o previsto e o realizado - conforme observações realizadas durante a pesquisa de campo ao longo de 1 semestre nas 2 escolas; e investimentos nas aulas e nos alunos financiados com recursos próprios.

Essa coerência e continuidade revelam o compromisso da participante para com a aprendizagem dos seus alunos. De acordo com Tancredi (2009, p. 47), o tempo de exercício profissional pode contribuir para o aperfeiçoamento do docente, “[...] quando há comprometimento com o ensino e interesse em se desenvolver profissionalmente, investindo no próprio sucesso, mas é fundamental que políticas públicas garantam condições efetivas de exercício e desenvolvimento profissional".

Assim, foi possível visualizar o desenvolvimento de boas práticas mediante as características já destacadas, as quais contribuem para o protagonismo e a aprendizagem do aluno nas aulas por meio de momentos de debate e reflexão a respeito do conteúdo estudado/vivenciado (na perspectiva da compreensão sobre o fazer), de experiências e saberes socializados e de construção do próprio conhecimento referentes às manifestações da "cultura corporal". 
Tomando-se por base os resultados da dissertação (COSTA, 2014), as práticas da professora de Educação Física foram fundamentais para refletirmos a respeito de sua concepção de conteúdos segundo os critérios que estabelece para escolhê-los, planejá-los, organizá-los e desenvolvê-los, bem como as contribuições pela maneira como desenvolve suas práticas para as aprendizagens dos seus alunos.

Por conseguinte, esses resultados apresentam as opções e ações da participante e contêm diversas características que contemplam a alfabetização e o letramento e contribuem para possibilidades de articulação e fortalecimento entre diferentes áreas do conhecimento. Essas características serão explicitadas no último tópico deste artigo.

\section{CONCLUSÃO}

A discussão com os resultados da dissertação (COSTA, 2014) elucidam múltiplas possibilidades de articulação entre as diferentes linguagens subsidiadas pela linguagem corporal como meio para o desenvolvimento da especificidade da Educação Física na escola.

Corroborando Petry (1988), Silva (1996), Ladeira e Darido (2003), Ladeira (2007), Cordeiro e Cordeiro (2015), Menegon et al. (2015) e Costa e Monteiro (2016), também admitimos as possibilidades de articulação entre as áreas em virtude do atendimento aos pressupostos fundamentais e comprobatórios da inserção da Educação Física na área de linguagens.

Considerando que a coleta de dados da pesquisa de mestrado foi realizada no período de 2012-2013, realizamos algumas aproximações com o que tem sido discutido atualmente, sobretudo a respeito da BNCC (BRASIL, 2016), documento que, ao propor a perspectiva de linguagens e o tratamento pedagógico das práticas corporais, contempla, entre outras questões, a interdisciplinaridade.

No documento, há a apresentação da perspectiva de linguagens e da proposta de integração entre diferentes componentes curriculares e áreas do conhecimento ao longo da Educação Básica. Na perspectiva das linguagens, a Educação Física contempla as práticas corporais, como "[...] textos culturais passíveis de leitura e produção, não devendo, portanto, ser limitadas apenas à reprodução" (BRASIL, 2016, p. 100). Logo, essa forma de entender a Educação Física possibilita e explica sua inserção na área de linguagens.

Nesse sentido, este artigo contribui tanto para o debate na área de linguagens, para o debate a respeito de interdisciplinaridade e quanto para as proposições do documento porque o trabalho docente em qualquer área exige ações interdisciplinares, pois o conhecimento apenas se desenvolverá se ocorrerem estes tipos de articulações. A formação pode-se tornar diferenciada a partir do momento em que o ensino assume uma postura interdisciplinar, ampliando a visão de mundo do aluno e suas interpretações referentes a acontecimentos e ações. Como consequência, conseguirá, com segurança, encontrar caminhos que desencadearão o desenvolvimento de todas as pessoas envolvidas. Conseguirá, ainda, encontrar as soluções, por exemplo, para os problemas e as dificuldades cotidianas. 
No eixo "conteúdo escolar", elucidamos diversas características, entre outras, representativas dessas possibilidades, a saber: conceito de "cultura corporal"; dimensões conceituais, atitudinais e procedimentais; necessidade de legitimação da área; relação com temas; diálogo com a literatura; critérios estabelecidos em sua seleção e organização; perspectiva de inserção da Educação Física na área de linguagens; conteúdos clássicos; contextualização do ensino; alunos como protagonistas; valorização dos conhecimentos prévios discentes; reflexão e compreensão sobre o fazer corporal; relação com os processos de alfabetização e de letramento; produção de textos (corporais ou não); interdisciplinaridade; e otimização do tempo e dos recursos. Além disso, a articulação com outras áreas do conhecimento possibilitou o fortalecimento entre os seguintes campos: Educação Física; História; Geografia; Matemática; Língua Portuguesa; Artes Cénicas; Artes Plásticas e outros.

Essas relações valiosas e férteis confirmam possibilidades que se relacionam com as questões das políticas públicas de formação de professores de Educação Física, pois, além de provocarem a sustentação da própria área, fomentam outros campos de formação.

Os conteúdos da Educação Física, os processos de alfabetização e de letramento (com base nos pressupostos da inserção da Educação Física na área de linguagens) e as diversas possibilidades de articulação entre diferentes áreas, são desenvolvidos simultaneamente por meio das características identificadas nas práticas da participante da pesquisa de mestrado. Além disso, o debate a respeito de possibilidades de boas práticas no contexto de início da carreira e a necessidade de políticas públicas de formação docente (sobretudo para professores de Educação Física iniciantes e atuantes nos anos iniciais do Ensino Fundamental) é consolidado pelas análises realizadas.

Assim, consideramos, com base em Fazenda (1996), que a forma como a participante da pesquisa de mestrado desenvolveu o conteúdo nas aulas de Educação Física nos anos iniciais se aproxima de um "pensar" e de um "fazer" interdisciplinar, em virtude: do diálogo com outros modos de conhecer; do compromisso com a aprendizagem dos alunos como um "ato de vontade"; da atitude de busca e pesquisa fundamentada na inexistência de uma proposta sistematizada dos conteúdos de Educação Física para os anos iniciais e nas preocupações referentes ao domínio do saber como ensinar; do diálogo entre conteúdos e referências teóricas e metodológicas que fundamentam a escolha e o planejamento desses conteúdos; do aprofundamento da cultura dos alunos por meio do diálogo entre essa cultura (local) e a cultura escolar; do uso da linguagem corporal como possibilidade de comunicação em distintas culturas e contextos e como possibilidade de interação dos alunos com a "cultura corporal"; da diversificação dos procedimentos para ensinar (pesquisa, leitura, escrita etc.) como possibilidade de ampliação do conhecimento do senso comum por meio do diálogo com o conhecimento científico, enriquecendo a "relação com o outro e com o mundo"; e de um planejamento com coerência entre razão e propósito.

Embora a diversificação dos procedimentos para ensinar (pesquisa, leitura, escrita etc.) não seja muito comum no que se refere ao tratamento pedagógico dos elementos da "cultura corporal" em razão de uma cultura de valorização da dimensão procedimental em detrimento das 
outras dimensões nas aulas de Educação Física, concordamos que devem ser considerados, também, como procedimentos próprios da área.

O conteúdo "Jogos Africanos", desenvolvido com base no "Dia da Consciência Negra", também pode ser trabalhado nas áreas de História e Geografia, uma vez que, ao recuperar determinados elementos da cultura africana, as tradições desse grupo étnico estarão presentes como, por exemplo, danças e lutas e seus aspectos históricos. Do mesmo modo, o desenvolvimento desses elementos, com considerações por suas regiões de origem - podendo ser provenientes do continente africano ou do próprio Brasil - e pelas circunstâncias que os circundaram/circundam, igualmente se assenta em uma perspectiva de ensino contextualizada e interdisciplinar. Em face do trabalho com os "Jogos Africanos", é válido mencionar a inclusão no currículo da rede de ensino, pela Lei 11.645, de 10 de março de 2008 (BRASIL, 2008), da obrigatoriedade do desenvolvimento da temática "História e Cultura Afro-Brasileira e Indígena", principalmente nas áreas de Arte, Literatura e História.

Logo, este artigo apresenta algumas reflexões a respeito de interdisciplinaridade, no sentido de proporcionar, também, a ocasião para outras indagações que, aqui, tampouco não pretendemos contemplar e/ou esgotar. Portanto, essas indagações podem apontar possíveis caminhos por meio de novas pesquisas que promovam um avanço significativo na compreensão e no fazer pedagógico do que é ou possa ser interdisciplinar, direcionadas de forma a contribuir para a professora participante da pesquisa de mestrado, para as escolas, para a SEDUC, para a Educação Básica etc.

\section{REFERÊNCIAS}

AGUIAR, C. S. et al. (2005). Principais dificuldades dos professores de Educação Física nos primeiros anos de docência: elementos para (re) orientação das disciplinas de Didática e Prática de Ensino do curso de licenciatura em Educação Física da UFU. Revista Motrivivência, ano XVII, n. 25, p. 37-55, dez. Disponível em: <https://periodicos.ufsc.br/index.php/motrivivencia/article/view/4694/3881>. Acesso em: 28 dez. 2016.

ANDRÉ, M. E. D. A. (1990). Etnografia da prática escolar. 2. ed. Campinas: Papirus.

BOGDAN, R.; BIKLEN, S. (1994). Investigação Qualitativa em Educação: uma introdução à teoria e aos métodos. Portugal: Porto Editora.

BORGES, C. (2005). A formação dos docentes de Educação Física e seus saberes profissionais. In: BORGES, C.; DESBIENS, J-F. (orgs.). Saber, formar e intervir: para uma Educação Física em mudança. Campinas: Autores Associados, pp. 157-190.

BRASIL. Casa Civil. (1996). Lei n. 9.394, de 20 de Dezembro de 1996. Estabelece as diretrizes e bases da educação nacional. Brasília: BSB, 20 de dezembro. Disponível em: 
<http://www2.camara.leg.br/legin/fed/lei/1996/lei-9394-20-dezembro-1996-362578normaatualizada-pl.pdf>. Acesso em: 10 jan. 2017.

BRASIL. Casa Civil. (2001a). Lei n. 10.328, de 12 de Dezembro de 2001. Introduz a palavra "obrigatório" após a expressão "curricular", constante do 3 do artigo 26 da lei n. 9.394, de 20 de dezembro de 1996, que estabelece as diretrizes e bases da educação nacional. Brasília: 12 de dezembro. Disponível em: <http://www.planalto.gov.br/ccivil_03/Leis/2003/L10.793.htm>. Acesso em: 04 jan. 2017.

BRASIL. Casa Civil. (2008). Lei n. 11.645, de 10 de março de 2008. Altera a Lei n. 9.394, de 20 de dezembro de 1996, modificada pela Lei n. 10.639, de 9 de janeiro de 2003, que estabelece as diretrizes e bases da educação nacional, para incluir no currículo oficial da rede de ensino a obrigatoriedade da temática "História e Cultura Afro-Brasileira e Indígena". Brasília: 10 de março. Disponível em: <http://www.planalto.gov.br/ccivil 03/ Ato2007-2010/2008/Lei/L11645.htm>. Acesso em: 20 abr. 2019.

BRASIL. Conselho Nacional de Educação/Secretaria de Educação Média e Tecnológica. (2000). Parâmetros Curriculares Nacionais: Ensino Médio. Diário Oficial da União, Brasília. Disponível em: <http://portal.mec.gov.br/seb/arquivos/pdf/blegais.pdf>. Acesso em: 25 dez. 2016.

BRASIL. Ministério da Educação. Conselho Nacional de Educação. (2001b). Diretrizes Curriculares Nacionais para a Formação de Professores da Educação Básica, em nível superior, curso de licenciatura, de graduação plena. Parecer CNE/CP 009/2001, de 08 de maio. Disponível em: <http://portal.mec.gov.br/cne/arquivos/pdf/009.pdf>. Acesso em: 01 jan. 2017.

BRASIL. Ministério da Educação. Conselho Nacional de Educação. (2015). Resolução n. 2, de 1 de julho de 2015. Define as Diretrizes Curriculares Nacionais para a formação inicial em nível superior (cursos de licenciatura, cursos de formação pedagógica para graduados e cursos de segunda licenciatura) e para a formação continuada. Resolução CNE/CP 2/2015, de 1 de julho. Disponível em: $\quad<$ http://portal.mec.gov.br/docman/agosto-2017-pdf/70431-res-cne-cp-002-03072015pdf/file>. Acesso em: 16 abr. 2019.

BRASIL. Ministério da Educação. Conselho Nacional de Secretários de Educação. (2016). Base Nacional Comum Curricular. Proposta Preliminar. 2 Versão Revista. Brasília: MEC, CONSED, abr.

BRASIL. Ministério da Educação e do Desporto (1997). Parâmetros Curriculares Nacionais:

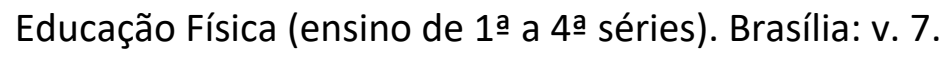

BRASIL. Ministério da Educação. Secretaria de Educação Básica. (2007). Ensino Fundamental de nove anos: orientações para a inclusão da criança de seis anos de idade. Brasília: ME, SEB. Disponível em: <http://portal.mec.gov.br/seb/arquivos/pdf/Ensfund/ensifund9anobasefinal.pdf>. Acesso em: 01 jan. 2017.

CASTELLANI FILHO, L. et al. (2009). Metodologia do Ensino de Educação Física. 2. ed. rev. São Paulo: Cortez.

CLARO Jr, R. S.; FILGUEIRAS, I. P. (2009). Dificuldades de gestão de aula de professores de Educação Física em início de carreira na escola. Revista Mackenzie de Educação Física e Esporte, 
Universidade Presbiteriana Mackenzie, v. 8, n. 2 pp. 9-24. Disponível em: <http://editorarevistas.mackenzie.br/index.php/remef/article/view/1718/1312>. Acesso em: 04 jan. 2017.

CORDEIRO, S. G.; CORDEIRO, R. V. (2015). Educação Física no contexto da alfabetização: pensando relações e possíveis contribuições. XIX Congresso Brasileiro de Ciências do Esporte (CONBRACE) $e$ VI Congresso Internacional de Ciências do Esporte (CONICE) - Territorialidade e diversidade regional no Brasil e América Latina: suas conexões com a Educação Física e ciências do esporte, 08 a 13 de setembro, Vitória, pp. 01-15. Disponível em: http://congressos.cbce.org.br/index.php/conbrace2015/6conice/paper/view/7107/3533. Acesso em: 04 jan. 2017.

COSTA, C. S. (2014). Práticas pedagógicas de uma professora de Educação Física "de início de carreira": um estudo de caso. 2013. 276f. Dissertação (Mestrado) - Programa de Pós-Graduação em Educação, Universidade Federal de São Carlos, São Carlos.

COSTA, C. S.; MONTEIRO, M. I. (2016). Educação Física na área de Linguagens, Códigos e suas Tecnologias (LCT): relações e contribuições possíveis. $X$ Congresso Nacional de Educação Física $e$ XXI Reunião Científica: "Práxis: baseando-se em evidência para revolucionar a prática", Bauru, nov. Disponível em: <https://sites.google.com/site/conefcombr/>. Acesso em: 05 jan. 2017.

COSTA, C. S.; VOLTARELLI, M. A.; CUNHA, R. C. (2012). Pesquisas sobre professores iniciantes: o estado do conhecimento no Programa de Pós-Graduação em Educação UFSCar de 2000-2010. III Congreso Internacional sobre Profesorado Principiante e Inserción Profesional a la Docencia, Santiago de Chile, fevereiro/março. Disponível em: <http://pt.slideshare.net/ProfessorPrincipiante/pesquisas-sobre-professores-iniciantes-o-estadodo-conhecimento-no-programa-de-posgraduaao-em-educaao-ufscar-de-20002010>. Acesso em: 04 jan. 2017.

CUNHA, M. I. (2014). O bom professor e sua prática. 24. ed. Campinas: Papirus.

FAZENDA, I. C. A (coord.) et al. (1996). Práticas interdisciplinares na escola. 3. ed. São Paulo: Cortez.

FERREIRA, L. A. (2006). O professor de Educação Física no primeiro ano da carreira: análise da aprendizagem profissional a partir da promoção de um programa de iniciação à docência. 2006. 216f. Tese (Doutorado) - Programa de Pós-Graduação em Educação, Universidade Federal de São Carlos, São Carlos.

FERREIRA, L. A.; REALI, A. M. M. R. (2009). O início da carreira docente na Educação Física. In: REALI, A. M. M. R.; MIZUKAMI, M. G. N. (org.). Complexidade da docência e formação continuada de professores. 1. ed. São Carlos: EdUFSCar, pp. 17-43.

FREIRE, J. B. (2010). Educação de corpo inteiro: teoria e prática da Educação Física. São Paulo: Scipione didático.

GALLARDO, J. S. P. (2010). Prática de ensino em Educação Física: a criança em movimento. Volume Único. São Paulo: FTD. 
GUARNIERI, M. R. (2005). O início na carreira docente: pistas para o estudo do trabalho do professor. In: (org.). Aprendendo a ensinar: o caminho nada suave da docência. 2. ed. Campinas: Autores Associados; Araraquara, SP: PPG em Educação Escolar da FCL da UNESP, pp. 5-23.

HUBERMAN, M. (1995). O ciclo de vida profissional dos professores. In: NÓVOA, A. (org.). Vidas de professores. 2. ed. Portugal: Porto Editora, pp. 31-61.

KAWASHIMA, L. B. (2010). Conteúdos de Educação Física para o ensino fundamental da rede municipal de Cuiabá: um estudo sobre sua sistematização. 2010. 196f. Dissertação (Mestrado) Instituto de Educação, Universidade Federal de Mato Grosso, Cuiabá.

LADEIRA, M. F. T. (2007). Linguagem e suas possibilidades na Educação Física escolar. 2007. $156 f$. Dissertação (Mestrado) - Instituto de Biociências, Universidade Estadual Paulista, Rio Claro.

LADEIRA, M. F. T.; DARIDO, S. C. (2003). Educação Física e Linguagem: algumas considerações iniciais. Motriz, Rio Claro, v. 9, n. 1, p. 31-39, jan./abr. Disponível em: <http://www.rc.unesp.br/ib/efisica/motriz/09n1/Ladeira.pdf>. Acesso em: 10 dez. 2016.

LEAL, P. H. (2011). A Educação Física no ciclo II do Ensino Fundamental: refletindo sobre indicadores educacionais de desenvolvimento profissional da docência com um professor experiente. 2011. 185f. Dissertação (Mestrado) - Programa de Pós-Graduação em Educação, Universidade Federal de São Carlos, São Carlos.

MELO, L. F. (2006). Do letramento ao corpo em movimento: um estudo sobre a Educação Física inserida numa proposta de educação. 2006. 128f. Dissertação (Mestrado) - Programa de PósGraduação em Educação, Universidade Vale do Rio dos Sinos, São Leopoldo.

MENEGON, R. R. et al. (2015). Educação Física e alfabetização: em busca de interlocução. Colloquium Humanarum, Presidente Prudente, v. 12, n. 4, pp. 130-138, out./dez. Disponível em: <http://revistas.unoeste.br/revistas/ojs/index.php/ch/article/viewArticle/1451>. Acesso em: 25 dez. 2016.

MINAS GERAIS (Estado). Secretaria de Estado da Educação. (2004). Orientações para $a$ organização do ciclo inicial de alfabetização. Caderno 2. Belo Horizonte: Centro de Alfabetização, Leitura e Escrita (CEALE). Disponível em: <https://www.educacao.mg.gov.br/images/stories/publicacoes/Caderno_2.PDF>. Acesso em: 01 dez. 2016.

MONTEIRO, M. I. (2010). Alfabetização e letramento na fase inicial da escolarização. São Carlos: EdUFSCar.

NONO, M. A. (2011). Professores iniciantes: o papel da escola em sua formação. Porto Alegre: Mediação.

PETRY, R. M. (1988). Educação Física e alfabetização. 3. ed. Porto Alegre: Kuarup.

ROSÁRIO, L. F. R.; DARIDO, S. C. (2005). A sistematização dos conteúdos da Educação Física na escola: a perspectiva dos professores experientes. Motriz, Rio Claro, v. 11, n. 3, pp. 167-178, 
set./dez. Disponível em: <http://www.rc.unesp.br/ib/efisica/motriz/11n3/10LRF.pdf>. Acesso em: 01 dez. 2016.

SANTOS, M. F.; MARCON, D.; TRENTIN, D. T. (2012). Inserção da Educação Física na área de Linguagens, Códigos e suas tecnologias. Motriz, Rio Claro, v. 18, n. 3, pp. 571-580, jul./set. Disponível em: <http://www.scielo.br/pdf/motriz/v18n3/a17v18n3.pdf>. Acesso em: 25 dez. 2016.

SILVA, R. B. et al. (2007). A Educação Física escolar em Maringá: experiências de ensinoaprendizagem no cotidiano das aulas. Rev. Bras. Cienc. Esporte, Campinas, v. 28, n. 02, pp. 69-83, jan. Disponível em: <http://www.revista.cbce.org.br/index.php/RBCE/article/view/56/64>. Acesso em: 13 dez. 2016.

SILVA, S. A. P. S. (1996). Educação Física escolar: relação com outros componentes curriculares. Motriz, v. 2, n. 2, pp. 65-71, dez. Disponível em: <http://www.rc.unesp.br/ib/efisica/motriz/02n2/2n2_ART02.pdf>. Acesso em: 24 dez. 2016.

SÃO PAULO (Estado). Secretaria da Educação. (2011a). Currículo do Estado de São Paulo: linguagens, códigos e suas tecnologias. 2 . ed. São Paulo: SE. Disponível em: <http://www.educacao.sp.gov.br/a2sitebox/arquivos/documentos/237.pdf>. Acesso em: $14 \mathrm{dez}$. 2016.

SÃO PAULO (Estado). Secretaria da Educação. (2011b). Regulamento do Curso de Formação Específica do Concurso Público para Professor Educação Básica II. São Paulo: SE, EFAP, jul. Disponível em: <http://www.rededosaber.sp.gov.br/portais/Portals/74/regulamento_conc_pub_peb2.pdf>. Acesso em: 14 dez. 2016.

SÃO PAULO (Estado). Secretaria da Educação. (2008). Revista São Paulo faz escola: edição especial da proposta curricular. São Paulo: CENPEC.

TANCREDI, R. M. S. P. (2009). Aprendizagem da docência e profissionalização: elementos de uma reflexão. São Carlos: EdUFSCar.

TARDIF, M. (2008). Saberes docentes e formação profissional. 9 ed. Petrópolis: Vozes.

\footnotetext{
' O Parecer apresentou as Diretrizes Curriculares Nacionais (DCN) para a formação de professores da Educação Básica, em nível superior, curso de licenciatura, de graduação plena (BRASIL, 2001b).

ii O programa contém dispositivos de melhorias para a qualidade da educação na rede estadual de ensino com base nas políticas públicas da SEDUC e sua finalidade incide em promover desenvolvimento profissional docente contínuo e em serviço (SÃO PAULO, 2011b).
} 